\title{
Tributo à Professora Anna Rachel Machado
}

Organizar uma entrevista póstuma com Anna Rachel Machado é uma enorme e profunda responsabilidade. Responsabilidade por poder partilhar trechos de construções marcadamente recheadas de emoçôes e motivaçôes da pessoa cativante e inteligente que nossa grande mestra foi. As perguntas feitas por amigos e profissionais $\mathrm{da}$ linguagem revelam uma parte $\mathrm{da}$ trajetória de trabalho de docência e de pesquisa que Anna Rachel realizou ao longo de sua vida profissional. O texto é uma homenagem para a pessoa de emoções intensas e produções impactantes ora na academia ora no cotidiano de amizades e de amores.

Saudade e admiração, querida Anna Rachel!

Vera Lúcia Lopes Cristovão (organizadora)

Anise de Abreu Gonçalves D’Orange Ferreira (UNESP) pergunta: Quais seriam as fontes das dificuldades de interpretação dentro do quadro do ISD?

\section{Professora Anna Rachel Machado responde:}

A tarefa de interpretação da teoria do ISD é difícil, pois dois tipos de problemas podem levar a interpretaçôes equivocadas: uns que derivam da sua própria especificidade e dos textos de seus autores nucleares e outros que derivam de textos de seus intérpretes. ${ }^{1}$ Dentre os primeiros, podemos elencar os seguintes:

\footnotetext{
${ }^{1}$ Estamos nomeando de intérpretes todos os pesquisadores leitores do ISD que não pertenceram oficialmente nem a seu núcleo original nem ao expandido.
} 
- O fato de o ISD ser uma vertente da Psicologia da Linguagem bastante complexa, que estabelece um diálogo intenso com uma quantidade significativa de autores de várias disciplinas das Ciências Humanas, o que nos exige um conjunto vasto de conhecimentos.

- O fato de o ISD ter-se constituído em uma relação dialética com a Didática de Línguas, disciplina essa que apresenta finalidades, questões e objetivos próprios, o que faz com que os textos dos autores aqui abordados, por circularem entre essas duas áreas, ${ }^{2}$ nem sempre apresentem homogeneidade de conceitos e/ou de termos.

- O fato de o ISD estar em contínua construção, o que exige uma leitura extensiva dos textos subjacentes aos atuais.

- O fato de seus autores, principalmente quando abordam questões de linguagem, utilizarem termos que têm valor diferente do que lhes é mais comumente atribuído, o que gera o risco de que sejam tomados no sentido mais consensual.

Outros problemas de interpretação das teses do ISD podem ser gerados por trabalhos de pesquisadores que tomam esse referencial teórico para pesquisas na área da Linguística Aplicada ou na da Didática de Línguas, frequentemente direcionados por finalidades educacionais práticas, o que pode determinar que utilizem apenas um aspecto particular da teoria, o que torna possível uma interpretação do ISD que toma a parte pelo todo. Mesmo assim, conscientes desses riscos, comecemos a trilhar nosso caminho interpretativo.

MACHADO, A. R. A perspectiva interacionista sociodiscursiva de Bronckart. In: MEURER, J. L; BONINI, A.; MOTTA-ROTH, D. (Org.). Gêneros, teorias, métodos, debates. São Paulo: Parábola, 2010. p.240.

\footnotetext{
${ }^{2}$ Observe-se que os autores, no decorrer do tempo, ora se (auto)-classificam como "psicólogos", ora como "psicólogos da linguagem", ora como "didactiens". Em comunicação oral no II Simpósio Internacional sobre Análise do Discurso: Discurso, Ação e Sociedade, na Universidade Federal de Minas Gerais, em 2002, Bronckart referiu-se a essa multiplicidade de rótulos, ainda acrescentando o de "lingüista" e o de "analista de discurso", afirmando que essa imprecisão não o preocupa, dado que não acredita na compartimentalização estanque das disciplinas que são associadas a esses rótulos.
} 
Ana Maria Guimarães (UNISINOS) pergunta: A consolidação do grupo ALTER $^{3}$ ocorreu ao longo dos últimos 10 anos, tendo em você a grande impulsionadora. Como começou a trajetória desse grupo?

\section{Professora Anna Rachel Machado responde:}

O Grupo ALTER começou em 2002, reunindo projetos de doutorandos e mestrandos do LAEL- PUC-SP, a partir de um projeto integrado, "Análise de Linguagem, Trabalho Educacional e suas relaçōes". Tomando o interacionismo sócio-discursivo (ISD, de ora em diante) como sua fonte de referência maior (Bronckart, 1999 e 2004), as pesquisas envolvidas nesse projeto associam os pressupostos teórico-metodológicos dessa teoria psicológica aos aportes da Ergonomia da Atividade (Amigues, 2004; Saujat, 2002 e 2004) e da Psicologia do Trabalho (Faïta, 2004; Clot, 1999). A conjunção dessas diferentes teorias não se dá de forma aleatória, mas sim, obedece a critérios que nos permitem uma coerência teórica, pois apenas assumimos vertentes e autores dessas disciplinas que desenvolvem uma abordagem marxiana do trabalho e/ou uma abordagem vigotskiana do desenvolvimento e/ou uma abordagem sóciodiscursiva da linguagem.

Os motivos que nos levaram à elaboração desse projeto foram vários: em primeiro lugar, a constatação da quase total inexistência de pesquisas, no Brasil e até mesmo no exterior, de pesquisas que enfoquem o ensino na sua dimensão de trabalho e com uma abordagem discursiva; em segundo lugar, nosso forte posicionamento contra um discurso generalizador, ideologicamente marcado, que considera o professor como um ser a quem sempre "falta" algo ("falta-lhe conhecimento", "falta-lhe reflexão", "falta-lhe vontade de mudar",

\footnotetext{
${ }^{3}$ O Grupo ALTER- Análise de Linguagem, Trabalho Educacional e suas Relações, nos anos posteriores, abriu-se para vários pesquisadores de todo o Brasil, sempre com a preocupação da análise da linguagem e do trabalho educacional. Marco inicial da constituição do grupo foi o simpósio realizado no $14^{\circ}$. InPLA, aos quais se seguiram, anualmente, vários eventos científicos nacionais e internacionais, com organização e participação da maioria dos integrantes do grupo. Exemplos disso foi a realização de do I Encontro Internacional do Interacionismo sociodiscursivo, na PUC/SP, o II Encontro, na Universidade Nova de Lisboa, em 2007, e, em 2009, o III Encontro, na PUC/Minas, assim como a I Jornada de Estudos do Núcleo de Estudos do Interacionismo Sociodiscursivo. Todos os anos, o grupo de pesquisadores, mestrandos e doutorandos reunia-se, no decorrer de algum congresso, com a finalidade de discutir seus rumos. O último encontro aconteceu em 2011, por ocasiāo do $18^{\circ}$. InPLA.
} 
etc.); e, finalmente, nossa firme convicção de que não sabemos o que é, de fato, o trabalho desse profissional, inclusive por estarmos, nós mesmos, nele engajados.

O objetivo comum das diferentes pesquisas do grupo é o de desenvolver um aprofundamento teórico-metodológico sobre as relações entre linguagem e trabalho educacional, considerados no quadro maior das relações entre discursos, atividades sociais e ações, por meio de análises de práticas de linguagem no e sobre o trabalho educacional.

MACHADO, A. R.; LOUSADA, E.; BARALDI, G; ABREU-TARDELLI, L.S.; TOGNATO, M. I. R. Relações entre linguagem e trabalho educacional: novas perspectivas e métodos no quadro do interacionismo sociodiscursivo. Calidoscópio, v. 2, n. 2, p. 89-95, jul/dez 2004.

Jean-Paul Bronckart (UNIGE - Universidade de Genebra) pergunta: Quelles sont, selon vos propres études, les spécificités du travail du professeur? Quais são, segundo seus próprios estudos, as especificidades do trabalho do professor?

\section{Professora Anna Rachel Machado responde:}

[...] não consideramos que o objeto do trabalho do professor seja algo como "auxiliar o aluno a se tornar um cidadão critico ou responsável" ou como "transformar os modos de pensar, agir e expressar-se de aluno", tal como algumas vezes tem sido formulado pelas prescrições institucionais ou por pesquisadores das ciências da educação. Na verdade, essas formulações podem ser consideradas não como objetos ou objetivos do professor, mas como finalidades propostas pelas prescrições, que só podem ser atingidas em um longo processo de desenvolvimento e não no trabalho do qui e do agora de um professor particular. Além disso, observe-se que, ao consideramos que o objeto é, de fato, criar um meio propício para a aprendizagem de conteúdos específicos das diferentes disciplinas e o desenvolvimento de capacidades específicas, não podemos dizer que o trabalho docente se limita aos limites da sala de aula, pois o processo de planejamento e o de avaliação são fases essenciais para essa criação.

Assim, o trabalho docente, resumidamente, consiste em uma mobilização, pelo professor, de seu ser integral, em diferentes situações - de planejamento, de aula, de avaliação -, com o objetivo de criar um meio que possibilite aos alunos a aprendizagem de um conjunto de conteúdos de sua disciplina e o desenvolvimento de capacidades específicas relacionadas a esses conteúdos, 
orientando-se por um projeto de ensino que lhe é prescito por diferentes instâncias superiores e com a utilização de instrumentos obtidos do meio social e na interação com diferentes outros que, de forma direta ou indireta, estão envolvidos na situação.

MACHADO, A. R. Por uma concepção ampliada do trabalho do professor. In: GUIMARÃES, Ana Maria de Mattos; MACHADO, Anna Rachel; COUTINHO, Antónia (Org.). O interacionismo sociodiscursivo. Campinas, Mercado de Letras, 2007. p. 77-97.

Eulália Leurquin (UFC) pergunta: Como você considera o trabalho do professor?

\section{Professora Anna Rachel Machado responde:}

Não consideramos que o objeto do trabalho do professor seja algo como "auxiliar o aluno a se tornar um cidadão crítico ou responsável ou transformar os modos de pensar, agir e expressar-se do aluno", tal como algumas vezes tem sido formulado pelas prescriçóes institucionais ou por pesquisadores das ciências da educação. Na verdade, essas formulações podem ser consideradas não como objetos ou objetivos do professor, mas como finalidades propostas pelas prescriçôes, que só podem ser atingidas em um logo processo de desenvolvimento e não no trabalho do aqui e do agora de um professor particular.

Eulália Leurquin (UFC) pergunta: Em que consiste o trabalho do professor? Professora Anna Rachel Machado responde:

O trabalho docente consiste em uma mobilização, pelo professor, de seu ser integral, em diferentes situaçóes - de planejamento, de aula, de avaliação , com o objetivo de criar um meio que possibilite aos alunos a aprendizagem de um conjunto de conteúdos de sua disciplina e o desenvolvimento de capacidades específicas relacionadas a esses conteúdos, orientando-se por um projeto de ensino que lhe é prescrito por instâncias superiores e com a utilização de instrumentos obtidos no meio social e na interação com diferentes outros que, de formas direta ou indireta, estão envolvidos na situação.

MACHADO, Anna Rachel. Uma experiência de assessoria docente e de elaboração de material didático para o ensino de produção de textos na universidade. In: ABREU-TARDELLI, Lília Santos; CRISTOVÃO, Vera Lúcia Lopes (Org.). Linguagem e Educação: o ensino e a aprendizagem de gêneros textuais. Campinas: Mercado de Letras Editora, 2009. p. 93-121. 
Didiê Ana Ceni Denardi (UTFPR) pergunta: As ciências da educação têm formulado que o objetivo do trabalho do professor é o de contribuir para o desenvolvimento de cidadãos críticos e responsáveis. Considerando-se essa premissa, o professor é visto como um dos principais responsáveis pela aprendizagem e emancipação crítico-social de seus alunos. Como você entende o trabalho docente?

\section{Professora Anna Rachel Machado responde:}

... o trabalho docente, resumidamente, consiste em uma mobilização, pelo professor, de seu ser integral, em diferentes situações - de planejamento, de aula, de avaliação -, com o objetivo de criar um meio que possibilite aos alunos a aprendizagem de um conjunto de conteúdos de sua disciplina e o desenvolvimento de capacidades específicas relacionadas a esse conteúdo, orientando-se por um projeto de ensino que é lhe é prescrito por diferentes instâncias superiores e com a utilização de instrumentos obtidos do meio social e na interação com diferentes outros que, de forma direta ou indireta, estão envolvidos na situação. (p. 93)

Didiê Ana Ceni Denardi (UTFPR) pergunta: Considerando-se que o trabalho docente é orientado "por um projeto de ensino prescrito por instâncias superiores”, que condiçôes são necessárias para que o professor desenvolva seu trabalho de forma efetiva?

\section{Professora Anna Rachel Machado responde:}

...é necessário que ele possa ter recursos materiais simbólicos, internos e externos, para: a) reelaborar continuamente as prescriçôes, mesmo antes de entrar em sala de aula, readaptando-as de acordo com a situação, com as reaçôes, interesses, motivaçóes, objetivos e capacidades de seus alunos, de acordo com seus próprios objetivos, interesses, capacidades e recursos (corporais, sociais, institucionais, cognitivos, materiais, afetivos etc). ), de acordo com as representaçōes que mantém sobre os "outros" interiorizados e sobre os critérios de avaliação que esses utilizam em relação ao seu agir; b) escolher, manter ou reorientar o seu agir de acordo com as necessidades de cada momento; c) apropriar-se de artefatos, transformando-os em instrumentos por si e para si, quando os considera úteis e necessários para seu agir: selecionar instrumentos adequados a cada situação; d) servir-se de modelos do agir socioistoricamente construídos por seu coletivo de trabalho; e) encontrar soluçôes para conflitos dos mais diversos (p. 93-4). 
MACHADO, A. R. Por uma concepção ampliada do trabalho do professor. In: GUIMARÃES, A. M. M.; MACHADO, A. R.; COUTINHO, A. (Org.). O Interacionismo Sociodiscursivo: questões epistemológicas e metodológicas. São Paulo Mercado de Letras, 2008. p.77-99.

Elvira Lopes Nascimento (UEL) pergunta: A profissão de professor é uma das mais valorizadas pela sociedade e ao mesmo tempo é aquela que mais está sendo negligenciada em todos os aspectos que a envolvem. Como você vê a atuação do linguista em relação a aquilo que você entende como o que é o trabalho do professor?

\section{Professora Anna Rachel Machado responde:}

Em uma visão ampliada sobre as relações entre lingüística e ensino, baseando-nos nos princípios do interacionismo sociodiscursivo e focalizando o papel dos lingüistas de um modo mais amplo, que não seja limitado ao fornecimento de conteúdos pertinentes para o ensino de línguas, defendemos a ideia de que sua atuação se faz e deve se fazer em uma escala muito mais ampla, até mesmo em relação a outras disciplinas escolares, uma vez que, nos processos de mediação formativa, é no quadro de textos produzidos nos três níveis da atividade educacional que são mobilizados os diferentes tipos de conhecimentos e se constroem representaçóes sobre o que deve ser o trabalho do professor, de qualquer nível e de qualquer disciplina. Uma vez que os textos em geral se constituem como objetos de análise tanto da Lingüística Textual quanto da Análise de Discurso, consideramos que temos, mais do que outras disciplinas, instrumentos privilegiados para a análise e a compreensão dos problemas que ocorrem em todos os níveis da atividade educacional.

Essa análise e compreensão pode ser associada a duas atitudes só aparentemente conflitantes: uma atitude crítica e uma atitude de colaboração em relação a processos que se desenvolvem na atividade educacional nos quais possamos ter a possibilidade de intervir direta ou indiretamente.

Assim, no processo de transposição didática inicial, no nível do sistema educacional superior, a colaboração dos lingüistas se faz na seleção dos conteúdos e práticas de linguagem a serem transpostos, no esforço de se fazer com que esses conteúdos e práticas sejam reunidos de forma coerente e para que os efeitos negativos das transposiçôes sejam os menores possíveis. Para isso, deveríamos levar em conta a existência de suporte teórico fornecido por estudos já desenvolvidos, o grau de validade desses conteúdos na área, o grau de consenso entre os especialistas, o grau de adequação para o trabalho do professor, consideradas as condições efetivas de trabalho, as condições que de 
fato existem para a apropriação desses conteúdos como instrumentos do trabalho, o grau de sua adequação para serem transformados em conhecimentos a serem ensinados e, enfim, seu grau de adequação para o desenvolvimento das capacidades de linguagem dos alunos. Ainda nesse nível, os lingüistas também muito contribuem na elaboração de conhecimentos científicos que sejam úteis tanto para a construção de materiais didáticos que possam ser apropriados pelos professores e alunos, quanto para a avaliação desses materiais e de experiências didáticas.

Já para uma atuação no nível do sistema didático, indispensáveis se fazem efetuarmos pesquisas que nos levem a uma melhor compreensão do que é o trabalho real do professor (cf. MACHADO, 2004). Isso implica analisar não só o que é efetivamente realizado, mas também as diferentes injunções externas, os artefatos materiais e simbólicos que são disponibilizados ou não para o cumprimento das prescrições oficiais, as dificuldades, impedimentos e conflitos que o professor enfrenta, a distância entre os conhecimentos científicos e as reais condições externas e internas que os professores têm para transformá-los em conhecimentos efetivamente ensinados e o modo como eles mesmos, atuando como atores responsáveis por seu trabalho, encontram soluçôes criativas para vencer esses impedimentos e conflitos.

A nosso ver, a atitude do lingüista não deve ser a de aceitação pura e simples do que é veiculado pelos textos de prescrição educacional. Faz-se necessária uma atitude analítica e crítica não só em relação aos conteúdos científicos selecionados, mas também quanto à forma como são transpostos, quanto às diretrizes, às finalidades, aos procedimentos e ao papel do professor, que são preconizados pelos documentos oficiais, desvelando a pretensa neutralidade desses documentos e as influências de outras atividades sociais e das ideologias subjacentes.

MACHADO, A. R. Colaboração e crítica: possíveis ações do linguista na atividade educacional. Veredas. Revista de Estudos Linguísticos, MG, v. 11, n. 2, p. 22- 40, 2007. Disponível: <http://www.ufff.br/revistaveredas/>. Acesso em: maio 2012. 
Maria Izabel Rodrigues Tognato (UNESPAR/FECILCAM) pergunta: Ao discutir os resultados de análise de dados coletados em uma atividade de formação de professores em 1998, tomando por base os conceitos de trabalho prescrito, trabalho planificado e trabalho realizado, como você (re)configuraria o papel do trabalho do professor formador na formação continuada de professores?

\section{Professora Anna Rachel Machado responde:}

A partir do que foi analisado, algumas conclusóes podem ser retomadas e outras podem ser avançadas no que diz respeito aos três níveis do trabalho de formação de professores e das suas inter-relações. Em primeiro lugar, observamos que, em relação ao trabalho prescrito, ao contrário do que ocorre em outras situações de trabalho, as prescrições sobre as formadoras - assessoras são feitas de forma vaga, dando-se uma relativa liberdade às suas açōes efetivas.

Em segundo lugar, quanto ao trabalho planificado, observa-se que a escolha do gênero de atividade pelas formadoras - assessoras, parecendo ser fortemente influenciadas pelos modelos configurados nos textos científicos da área da psicologia do desenvolvimento e da linguística a que as mesmas atribuem um valor de verdade. Além disso, verificamos que o texto planificador tem uma tripla função: ao mesmo tempo em que prefigura as ações, já é uma parte do trabalho realizado pelas formadoras - assessoras e é prescritivo das açôes a serem desenvolvidas pelos professores, conforme a expectativa da instituição. Mas, se as formadoras-assessoras se mostram em conformidade com a prescrição institucional, colocando-se como agentes responsáveis pelas transformações almejadas nos professores, também se mostram parcialmente afastados dela, na medida em que buscam dividir a responsabilidade com os professores, pelo menos no trabalho planificado.

Já no trabalho efetivamente realizado; de fato, embora os professores participem dele ativamente, o material didático, ele foi construído pela formadora - assessora A1. Além disso, a análise da interação nos mostra que é ela també que assume com mais intensidade a responsabilidade por sua condução. Assim, poderíamos considerar que surge aí uma "contradição" entre o planificado e o realizado. Entretanto, falar em contradição apenas nada nos explica. $\mathrm{Na}$ verdade, podemos dizer que o afastamento do trabalho realizado em relação ao planificado indica a força maior da prescrição institucional nesse trabalho específico. Em outras palavras, há duas intençôes que se realizam nas ações concretas do formador: de um lado, oriunda das teorias assumidas, a de desenvolver um processo em que os professores sejam agentes do processo de 
reestruturação do ensino; mas, de outro, oriunda das prescriçōes institucionais, a de fazê-los se transformar.

Além disso, também observamos que o trabalho planificado e o realizado das formadoras - assessoras também se distanciam em relação aos ambientes planejados e criados para essa possível transformação. Como vimos, o ambiente previsto nos textos de planificação fica sujeito, no trabalho efetivamente realizado, a interferências diretas dos professores, que o transformam, tornando presentes objetos discursivos referentes a aspectos materiais de suas práticas diárias na sala de aula, que não são minimamente considerados na planificação das formadoras.

Diante disso, restam-nos algumas perguntas: em que medida, ao dizermos que a formação de professores atual se volta para o cotidiano da sala de aula, para a experiência desses profissionais, ainda não estamos nós, os formadores, muito atados às teorias que assumimos? Em que medida podemos compreender as dificuldades da organização material do trabalho do professor? Em que medida podemos planificar ações de formação em que nos aproximemos mais desse trabalho efetivo? A meu ver, para respondê-las de forma adequada e buscarmos atingir o ideal sobre experiência e teoria em relação dialética, muitas e muitas pesquisas deverão ser feitas, para que ele seja compreendido em todas as suas dimensões, e não apenas nas cognitivas e didáticas, da mesma forma que o fizemos aqui, em relação ao trabalho do formador.

MACHADO, Anna Rachel. Trabalho prescrito, planificado e realizado na formação de professores: primeiro olhar. In: MACHADO, Anna Rachel e colaboradores; ABREU-TARDELLI, Lilia; CRISTOVÃO, Vera Lúcia Lopes (Org.). Linguagem e educação: o trabalho do professor em uma nova perspectiva. Posfácio Jean-Paul Bronckart. Campinas, SP: Mercado de Letras, 2009. (Série Ideias sobre Linguagem)

Angela B. Kleiman (UNICAMP) pergunta: Você afirma, em trabalho recente, que um instrumento não é simplesmente um objeto pronto, mas é algo que é construído pelo sujeito e por ele utilizado para atingir os objetivos de sua ação e que, por isso, o uso de um novo instrumento provoca transformações tanto no ambiente físico e social, em que se desenvolve a atividade, quanto nos que interagem com o sujeito e também no próprio sujeito. E propõe que é preciso conhecer a gênese ou a construção interna dos instrumentos para entender melhor a questão de apropriação dos gêneros no trabalho docente. O que seria a gênese dos instrumentos? 


\section{Professora Anna Rachel Machado responde:}

A distinção desenvolvida por Rabardel, 1995, entre os conceitos de "artefato" e de "instrumento", com grande aceitação por parte de inúmeros pesquisadores neovygotskyanos, é fundamental para compreendermos essa "gênese instrumental". Assim, o autor, tanto em trabalhos individuais quanto em coautoria, defende a ideia de que

An activity consists of acting upon an object in order to realize a goal and give concrete form to a motive. Yet the relationship between the subject and the object is not direct. It involves mediation by a third party: the instrument [...] An instrument cannot be confounded with an artifact. An artifact only becomes an instrument through the subject's activity (BÉGUIN E RABARDEL, 2000, p. 175).

Além disso, o instrumento não pode ser reduzido ao artefato material ou simbólico, assim como o termo "artefato" não é usado apenas para os "objetos" materiais, mas também para os dispositivos simbólicos, ambos sóciohistoricamente construídos e disponibilizados para mediarem a ação do homem sobre o meio ou sobre o outro e para que determinadas atividades sejam atingidas. Entretanto, nenhum artefato, exterior ao sujeito, em si mesmo, pode servir como um elemento mediador da ação humana. Torna-se necessária a apropriação pelo e para o próprio sujeito de construções representativas referentes ao instrumento, à realidade sobre a qual ele pode agir ou analisar, o que envolve a construção de estruturas que permitem a organização da ação do sujeito, ou dos chamados "esquemas de utilização". Desse modo, para o autor, o instrumento é uma entidade mista, constituída por um componente de artefato (um artefato, parte de um artefato ou um conjunto de artefatos) e por um ou vários esquemas de utilização a ele associados, resultante de uma construção do sujeito ou de sua apropriação de esquemas socialmente preexistentes. Esses esquemas de utilização se constituem como estruturas ativas, nas quais as experiências passadas são incorporadas e organizadas, de modo que se tornam referências para a interpretação de novos dados.

Assim, compreendemos que "apropriar-se" é o processo de adaptar alguma coisa a um uso ou a uma finalidade determinada; atribuir alguma coisa a si mesmo, fazer com que ela seja SUA (algumas vezes, de modo até mesmo indevido). Em outras palavras, em situação de trabalho, o trabalhador não utiliza os artefatos simplesmente como the determinam as prescrições, mas do modo que julgar útil para si mesmo e para sua ação, de acordo com a situação em que se encontrar. 
MACHADO, Anna Rachel. Ensino de gêneros textuais para o desenvolvimento do professor e de seu trabalho. In: SERRANI, Silvana (Org.). Letramento, discurso e trabalho docente. Vinhedo, SP: Editora Horizonte, 2010. p. 163-164.

Eliane Lousada (USP) pergunta: Escutamos e lemos frequentemente a afirmação de que os gêneros são instrumentos, o que tem sido objeto de várias polêmicas. $\mathrm{O}$ que significa, para o interacionismo sociodiscursivo, essa afirmação?

\section{Professora Anna Rachel Machado responde:}

[A nosso ver, tanto essa prescrição dos PCNs quanto] muitas das pesquisas desenvolvidas trazem, de modo implícito ou explícito, o pressuposto de que "o gênero pode ser considerado como um instrumento psicológico no sentido vygotskiano do termo, ou seja, no sentido em que o termo instrumento foi reinterpretado, por Rabardel (s/d)" (SCHNEUWLY, 2004, p. 24). E é esse pressuposto que alicerça a tese de cunho didático de que os gêneros de texto devem ser o centro do processo de ensino de produção e compreensão. Entretanto, consideramos que as pesquisas desenvolvidas ainda deixaram lacunas. Uma delas é a falta de clareza sobre o conceito de instrumento psicológico, muitas vezes compreendido no sentido do senso comum, isto é, como um objeto material existente fora do sujeito, tanto pelos que aceitam a tese defendida por Schneuwy $(1994,2004)$ quanto pelos que a rejeitam. Essa nossa afirmação encontra eco em Rabardel (2002), quando este afirma que a ideia de ferramenta ou de instrumento acaba sendo tomada em seu sentido concreto, de senso comum, confundindo-se com o objeto físico. Segundo Rabardel (1995, p. 56), essa concepção pode ser suficiente no âmbito tecnológico, porém ela é insuficiente para analisar a situação do ponto de vista do homem engajado na ação. Para tanto, seria necessário construir uma conceituação psicológica da noção de instrumento.

$[\ldots]$

A primeira (interpretação negativa do trabalho com gêneros no Brasil) foi uma visão muito simplista ou de senso comum da metáfora "gênero é ferramenta/instrumento". Por exemplo, tomando os termos não como conceitos metafóricos, mas como se referindo a um objeto material ou a algo equivalente. A segunda foi a interpretacão dos termos no quadro de concepções de linguagem utilitaristas ou representacionalistas, o que levou muitos linguistas sérios a se manifestarem contra os PCNs. A nosso ver, para compreendermos a metáfora de Schneuwly (1994): "gênero é um instrumento" 
ou "a sequência didática é um artefato que pode se constituir em um instrumento do trabalho do professor" é necessário compreender "instrumento" como conceito construído no quadro da psicologia vigotskiana tanto por Vygotsky (1934/2001) quanto por pesquisadores que desenvolvem suas idéias. É necessário, portanto, retomar duas questões básicas: a) $\mathrm{Na}$ perspectiva da teoria psicológica vygostkiana e de seu desenvolvimento atual, o que são instrumentos psicológicos? e, b) Que efeitos provocam no meio e nos indivíduos envolvidos na atividade em que são utilizados? Primeiro, quando se fala em "instrumento" como conceito da psicologia, não se fala de algo que está aí, pronto, "dado" pela natureza ou pela sociedade, de um objeto material que existe fora do sujeito, que se pode pegar com as mãos, mas de algo que é construído pelo sujeito e por ele utilizado para atingir o objetivo de sua ação. Segundo, o uso de um novo instrumento vai provocar transformações no ambiente físico ou social, nos outros que interagem com o sujeito, mas também sobre ele mesmo, fazendo com que ele tenha profundas transformaçóes psíquicas, ou seja, aumente seus conhecimentos sobre o mundo físico e social, desenvolva capacidades para agir sobre o outro e sobre o mundo e regule seu comportamento. Mas, de onde provêm esses instrumentos psicológicos? Como se constroem? Para responder a essas perguntas, é necessário compreender a distinção entre artefato e instrumento, proposta por Rabardel (1995) e retomada por Schneuwly $(1994,2004)$ para a discussão do papel dos gêneros no desenvolvimento. Assim, nessa perspectiva, os artefatos são "objetos" materiais ou simbólicos, sócio-historicamente construídos para mediarem a ação do homem sobre o meio ou sobre o outro e para se atingirem determinadas finalidades. Entretanto, nenhum artefato, em si mesmo, pode servir como esse elemento mediador da ação humana. Por exemplo, não é a simples existência social dos gêneros textuais (ou discursivos) que garante a possibilidade de comunicação em um determinado contexto. Não é a simples colocação de computadores em sala de aula que levará automaticamente a que o aluno obtenha as informações que lhe são necessárias. É preciso desmistificar essa visão e compreender que os artefatos são colocados à disposição dos trabalhadores, em uma determinada época e em uma determinada sociedade, mas que existe a necessidade de o trabalhador apropriar-se do artefato. Consideramos que "apropriar-se de alguma coisa" é adaptar alguma coisa a um uso ou a uma finalidade determinada; atribuir alguma coisa a si mesmo, fazer com que ela seja SUA (algumas vezes, até mesmo de modo indevido). De fato, segundo Rabardel (1995), o artefato nunca é apropriado em sua totalidade, 
mas em parte, de acordo com as necessidades dos sujeitos, de suas capacidades, da situação etc. Em outras palavras, não se trata de simplesmente utilizar o artefato como mandam as prescrições, mas de usá-lo de modo que ele seja útil para o próprio trabalhador e adaptado por ele mesmo às diferentes situaçóes em que precisa utilizá-lo. Assim, é só quando algum artefato é apropriado pelo sujeito que ele passa a ser verdadeiro instrumento psicológico, na concepção da teoria vigotskiana. Trata-se, portanto, de uma construção psíquica, que permite o desenvolvimento de diferentes capacidades. Em relação aos gêneros, eles só poderão servir de mediadores para a comunicação e para o desenvolvimento linguageiro se forem apropriados pelo sujeito.

MACHADO, A. R; LOUSADA, E. G. A apropriação de gêneros textuais pelo professor: em direção ao desenvolvimento pessoal e à evolução do métier. Linguagem em (Dis)curso, Palhoça, SC, v. 10, n. 3, p. 619-633, set./dez. 2010.

Acir Mário Karwoski (UFTM) pergunta: Você propôs a sugestão de uma visão mais ampla sobre a relação "Linguística e ensino". Resumiu a visão mais tradicional expandindo-a, recorrendo a aportes de outras disciplinas. Sua visão sobre as relações entre linguística e ensino é, no entanto, mais ampliada. Em que consiste essa visão?

\section{Professora Anna Rachel Machado responde:}

Não podemos nos esquecer que as diferentes influências dos estudos linguísticos não se deram isoladamente e ao acaso, mas no quadro do desenvolvimento concomitante de outras disciplinas. Em primeiro lugar, no da psicologia, com a influência sucessiva do behaviorismo, do cognitivismo piagetiano e da psicologia vigotskiana. Em segundo lugar, com o desenvolvimento das pesquisas da Linguística Aplicada, voltadas, sobretudo, já no final dos anos 1970 e no início dos anos 1980, para as questóes de ensino de línguas, da produção e da compreensão de textos em seu uso efetivo. Além disso, queremos observar que as abordagens da relação Linguística e ensino como a de Marcuschi (2001), na verdade, embora sejam esclarecedoras, versam, de fato, apenas sobre as relações entre os saberes construídos e privilegiados pelos paradigmas dominantes na Linguística em uma determinada época (determinadas, evidentemente, pelas concepções sobre língua e linguagem) e a sua influência no ensino. Não se abordam outros tipos de relações que podem ser levantadas, se levarmos em conta a complexidade da atividade educacional, com os seus diferentes sistemas e suas relaçóes com outras atividades sociais. É essa tentativa que faremos a seguir, tomando como 
ponto de apoio central as proposiçôes mais amplas do interacionismo sociodiscursivo (ISD), quadro teórico que guia nossa reflexão e que exporemos a seguir. (...) O ISD é uma corrente das ciências humanas, que se baseia em uma articulação das obras de Spinoza, Marx e Vygotski, buscando desenvolver um programa de pesquisa voltado para a construção de uma "ciência do humano", a fim de atingir uma compreensão mais ampla da complexidade do funcionamento psíquico e social dos seres humanos. Não se pode dizer, portanto, que seja uma teoria da lingüística ou da psicologia, pois, sendo constitutivamente transdisciplinar, o ISD não pode ser confinado a nenhum desses quadros disciplinares de forma estanque. A principal ideia defendida é a de que o desenvolvimento dos indivíduos ocorre em atividades sociais, em um meio constituído e organizado por diferentes pré-construídos e através de processos de mediação, sobretudo os linguageiros. (...) Assume-se o papel fundador da linguagem e principalmente da atividade discursiva no desenvolvimento humano. (...) Dado esse papel central da atividade discursiva, as pesquisas do ISD dão ênfase especial à análise e interpretação de textos (orais ou escritos), manifestação concreta dessa atividade, centrando-se, mais frequentemente, no estudo de situações de mediação formativa (de ensino ou de trabalho). Consequentemente, fazer estudos na linha do ISD implica um estudo permanente dos aportes das ciências da linguagem - e mais especificamente da linguística do texto e do discurso -, assim como o desenvolvimento de pesquisas próprias sobre o funcionamento dos textos nessas situações, o que, a nosso ver, implica fazer linguística. (...) Quando nos voltamos para a resolução de algum problema concreto, como o do ensino, as pesquisas não podem ser caracterizadas como pesquisas simplesmente aplicadas, pois, no próprio processo de análise desses problemas, estamos continuamente checando os modelos assumidos e, quando necessário, reformulando-os, quando isso se mostra necessário, o que acaba - acreditamos - por trazer novos conhecimentos para a própria área da lingüística. Do mesmo modo, quando aparentemente nos voltamos para a resolução de problemas "teóricos", por mais teóricos que sejam, mesmo que não haja intervenção prática imediata, mais cedo ou mais tarde, os resultados dessas pesquisas terão a sua validade testada na sua operacionalização prática.

MACHADO, A. R. Colaboração e crítica: possíveis ações do linguista na atividade educacional. In: ABREU-TARDELLI, L. S.; CRISTOVĀO, V. L. (Org.). Linguagem e educação: o ensino e a aprendizagem de gêneros textuais. Campinas, SP: Mercado de Letras, 2009. p. 43-70 
MARCUSCHI, L. A. O papel da linguística no ensino de línguas. Investigaçôes, Recife - UFPE, n.13/14, p. 187-218, 2001.

Vera Lúcia Lopes Cristovão (UEL) pergunta: Como propõe o uso de capacidades de linguagem na relação com materiais didáticos?

Professora Anna Rachel Machado responde:

[...] um instrumento de descrição e de avaliação das sequências didãticas, que, com as devidas ressalvas, pode ser utilizado em diferentes situaçóes de avaliação de outros materiais didáticos destinados ao ensino/aprendizagem da produção textual, permitindo uma reflexão maior sobre esses materiais e sua contínua reelaboração de acordo com as características de um determinado contexto educacional. Consideramos, portanto, que esse instrumento pode ser extremamente útil em trabalhos de formação contínua de professores, quer seja para orientar a produção e a avaliação de material didático por eles produzido, quer seja para fornecer-lhes critérios para uma progressão curricular sistematizada ou para a análise e escolha de material didático pertinente ao desenvolvimento e às necessidades reais de seus alunos.

MACHADO, Anna Rachel. Um instrumento de avaliação de material didático com base nas capacidades de linguagem a serem desenvolvidas no aprendizado de produção textual. In: ABREU-TARDELLI, Lília Santos; CRISTOVÃO, Vera Lúcia Lopes (Org.). Linguagem e Educação: o ensino e a aprendizagem de gêneros textuais. Campinas: Mercado de Letras Editora, 2009. p. 153-164.

Regina Celi Mendes Pereira (UFPB) pergunta: Em meio à efervescência teórica dos estudos sobre os gêneros textuais, particularmente nos últimos quinze anos, e suas implicações na formação docente tanto no Brasil como no Exterior, como o quadro teórico do Interacionismo Sociodiscursivo (ISD) concebe o ensino-aprendizagem de gêneros?

\section{Professora Anna Rachel Machado responde:}

Não há possibilidade de identificar, descrever e classificar todos os gêneros existentes em nossa sociedade, muito menos ensiná-los. Inexoravelmente, nossas análises, descrições, e classificações sempre serão parciais, justificadas apenas por objetivos específicos. Assim, os chamados modelos didáticos de gêneros que buscamos construir têm de ser vistos como uma possibilidade dentre outras, e não como o modelo único e definitivo, devendo eles ser sempre orientados pelos objetivos educacionais que perseguimos. A clareza que devemos ter sobre essa parcialidade parece ser fundamental, uma 
vez que ela pode impedir-nos de abordá-los, principalmente no ensino e na formação de professores, como "modelos" intocáveis e invariáveis e levar-nos à consciência de que as restriçôes sociais deixam sempre, a todo momento, em cada ação, uma brecha, uma "falha", uma incompletude por onde podemos deslizar. Do mesmo modo, reconhecendo essa incompletude no próprio modelo de análise do ISD, consideramos que ele não pode - e não deve, e não quer - ser tomado mecanicamente ou unidirecionalmente, mas apenas como uma ferramenta, que, ao lado de outras situaçōes concretas, compreendendose a complexidade da ação humana e tomando-se os textos como um espaço em que a dialética entre a criatividade da ação humana e as restrições do social se mostra do modo mais evidente, inclusive no quadro das atividades educacionais. Assim, o ensino dos gêneros terá seu sentido assegurado se soubermos claramente o que queremos dizer com isso e se tivermos a perspectiva clara de que, paradoxalmente, é o seu domínio que nos pode permitir deles "escapulir".

MACHADO, A.R. A perspectiva interacionista sociodiscursiva de Bronckart. In: MEURER, J.L.; BONINI, A.; MOTTA-ROTH, D. (Org.). Gêneros: teorias, métodos, debates. São Paulo: Parábola Editorial, 2005. p. 258-259.

Ecaterina Bulea Bronckart (UNIGE - Universidade de Genebra) pergunta: Concernant ta thèse de doctorat, en quoi la méthodologie de l'ISD at-elle été utile, et quelles sont les principales conclusions didactiques de ce travail? Em relação a sua tese de doutorado, em que a metodologia do ISD foi útil e quais são as principais conclusões didáticas desse trabalho ?

\section{Professora Anna Rachel Machado responde:}

Em relação aos procedimentos de análise que foram adotados, consideramos que a combinação que idealizamos do método proposto pela equipe de Genebra com a análise das representações sobre a situação de comunicação e do gênero configura-se como bastante produtiva para a interpretação de situações de produção complexas, como o são habitualmente as situações didáticas, permitindo a visualização de várias outras pesquisas que a partir daí podem ser desenvolvidas. Além disso, essas análises nos permitiram conceptualizar um modelo de diário de leituras, de forma mais produtiva, o que possibilita que os professores orientem melhor os alunos e que possam fornecer-lhes um instrumental par autocrítica em outras experiêncas semlhantes à que foi enfocada. 
A análise mais completa que fizemos de um número bastante representativo de diários produzidos, e não simplesmente de recortes que favorecessem os nossos pressupostos iniciais, possibilitou uma avaliação mais completa da atividade desenvolvida em sala de aula. Essa avaliação permite-nos tomar uma distância maior entre aquilo que pressupúnhamos inicialmente e o que realmente ocorreu, evitando-se, assim, concepções ingênuas de que um instrumento didático qualquer possa ser mágico em si mesmo, o que se faz freqüentemente em muitos trabalhos de pesquisa.

MACHADO, A. R. O Diário de leituras. A introdução de um novo instrumento na escola. São Paulo. Martins Fontes, 1998. p. 242-243.

Lília Santos Abreu-Tardelli (IF-SP) pergunta: De que modo a escrita pessoal é importante para o desenvolvimento da escrita de gêneros públicos? Nesse sentido, qual a importância do ensino do diário de leitura numa visão vigotskiana de ensino e aprendizagem para ajudar o aluno na produção dos gêneros públicos?

\section{Professora Anna Rachel Machado responde:}

Vemos que nas reformas educacionais brasileiras levadas a cabo no final da década de 90, "experts" privilegiaram o ensino dos chamados "gêneros públicos” (Brasil, MEC/SEF 1998), esquecendo-se do valor heurístico da escrita dos chamados gêneros privados. Mesmo em relação ao ensino da produção dos gêneros públicos, não se tem dado a ênfase necessária às dimensóes e escolhas pessoais, à ação do sujeito orientada a partir de si mesmo, à apropriação do gênero por si e para si, à sua estilização, tudo isso sendo fundamental para sermos proficientes em um gênero público e sendo este $o$ sentido maior da função do signo para Vigotski: só quando verdadeiramente apropriado, é que ele se constitui em um instrumento para o sujeito agir sobre o mundo e sobre si mesmo, fazendo desse "si mesmo" um objeto de pensamento e de ação.

Além da preferência de nossos "experts" pelos gêneros públicos, parece ainda haver uma compreensão equivocada a respeito do diário de leituras, que o leva a ser considerado um gênero "monológico" (como se pudesse haver esse tipo de gênero), não se reconhecendo que, mesmo que seja um gênero privado no processo inicial de sua produção, ele se configura como um artefato que pode tornar-se instrumento de reflexão, desencadeador de múltiplos diálogos - internos e externos. Além disso, parece haver uma concepção errônea de que o diário de leituras seria depositário "apenas" dos sentimentos de leitor. Essa 
concepção sobre o diário, embora não verdadeira, revela, implicitamente, um certo mentalismo e intelectualismo diretamente relacionados à adoção de uma psicologia de fato cognitiva, mesmo que se declare, de forma explícita, a adoção da psicologia vigotskiana. Os que tomam essa posição, na verdade, negam o papel das emoçôes no desenvolvimento humano, não compreendendo que "a tradição vigotskiana está totalmente ligada à elaboração de uma teoria da consciência, relacionando, na atividade, o pensamento, a linguagem e as emoções do sujeito" (Clot, 1999/2000, p. 15, tradução da autora) e não levando em consideração a afirmação do próprio Vygotsky, segundo a qual "são exatamente as paixões que constituem o fenômeno fundamental da natureza humana” (Vygotsky 1993/1998, p. 267, tradução da autora).

MACHADO, Anna Rachel. Diários de leitura: a construção de diferentes diálogos na sala de aula. In: MACHADO, Anna Rachel. Linguagem e Educação: o ensino e a aprendizagem de gêneros textuais. ABREU-TARDELLI, Lília Santos; CRISTOVÃO, Vera Lúcia L. (Org.). Campinas, SP: Mercado de Letras, 2009, p. 74-75. (Série Ideias sobre Linguagem)

Ana Paula Marques Beato-Canato (UFRJ) pergunta: Professora Anna Rachel, em meio a um currículo tão vasto, há uma outra faceta sua bem marcante, a de poetisa, que poucos conhecem e que traz boas recordações a muitos de nós. Gostaria que falasse um pouco de seu livro, do processo de escrita e do papel da escola.

\section{Professora Anna Rachel Machado responde:}

"Eu não consigo dizer que isso é um livro de poesia. [...] É uma escrita intima ou, como diz o meu prefaciador mor, o Egon de Oliveira Rangel: "Estes poemas são fragmentos do discurso amoroso" e caracteristicamente um discurso amoroso feminino feminista (gargalhadas). [...] Nunca [tinha publicado]. Era reservado, eu mostrava pra pouquíssimas pessoas. A gente morria de vergonha, porque como eu sou [acadêmica].... Há muita gente que diz que há muito poeta, muito escritor, que acaba com sua tendência poética porque vai fazer filosofia, vai fazer faculdade. Eu acho que a escola em geral e isso é uma das missóes desse livro, [...] - desde quando a gente é criancinha, você é boicotado na sua escritura intima. Só te ensina aquilo que é muito pragmático. $\mathrm{Na}$ verdade, [a escola] encara a linguagem somente como comunicação e não com seu valor heurístico, de descoberta, de autoconhecimento. Então, uma das missões minhas ao publicar esse livro foi meio mostrar isso também e dar coragem a outras pessoas [...] 


\section{Ando tão plena de poesia}

que o máximo que posso te enviar

são gotas do meu azul silêncio.

MACHADO, Anna Rachel. Entrevista concedida a Atilio Bari e Roberta Bari, no Programa da Tv Aberta. São Paulo, 04 set. 2009. Disponível em: <http:// www.youtube.com/watch?v=HqGrhVk1umA>. Acesso em: 21 maio 2012.

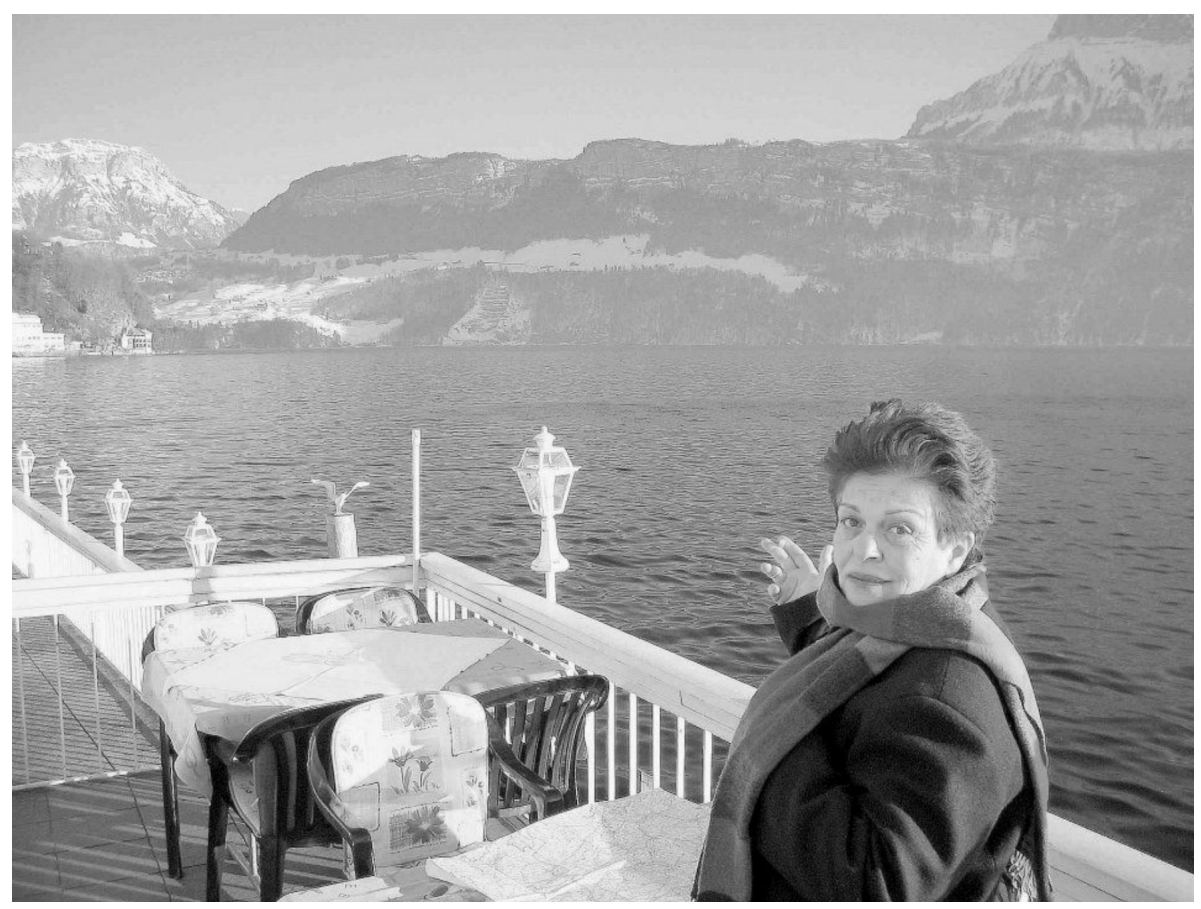

